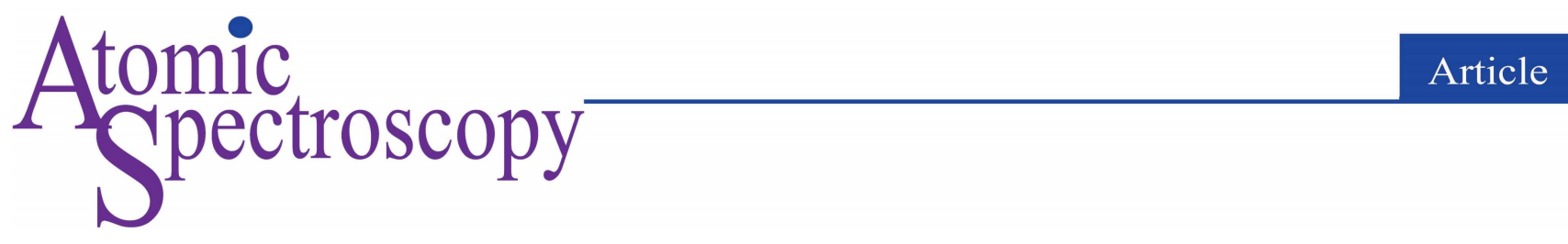

\title{
Comparison of Three Sequential Extraction Methods for the Determination of Iron, Manganese, and Thallium in Asphaltite Samples
}

\author{
Oyku Bilgin, ${ }^{\mathrm{a}}$ Celal Fidan, ${ }^{\mathrm{b}}$ Isil Aydin, ${ }^{\mathrm{c}}$ and Firat Aydin ${ }^{\mathrm{b}, *}$ \\ a Department of Mining Engineering, Faculty of Engineering, Sirnak University, Sirnak, Turkey \\ b Department of Chemistry, Faculty of Science, Dicle University, Diyarbakir, Turkey \\ c Department of Analytical Chemistry, Faculty of Pharmacy, Dicle University, Diyarbakir, Turkey
}

Received: 11 August 2020, Revised: 14 September 2020, Accepted: 14 September 2020, Available online: 19 September 2020.

DOI: $10.46770 / A S .2020 .05 .004$

ABSTRACT: Asphaltite, which is based on petroleum, contains many elements that exist in different forms. In this study, the BCR sequential extraction (BCRSE), Tessier sequential extraction (TSE) and Stover sequential extraction (SSE) procedures were applied for the determination of $\mathrm{Fe}, \mathrm{Mn}$ and $\mathrm{Tl}$ in different forms (exchangeable, carbonates, bound to organic and sulfide, and residual content) in the structure of asphaltite. The statistical relations between the metal values of the three different methods were determined and recommendations are given for the enrichment of these economically valuable elements from asphaltite samples. The most abundant form of $\mathrm{Fe}(\%), \mathrm{Mn}\left(\mathrm{mg} \mathrm{kg}^{-1}\right)$ and $\mathrm{Tl}\left(\mathrm{mg} \mathrm{kg}^{-1}\right)$ follows the order: reducible (2.28), residual (75.85) and residual (81.99) with BCRSE method; carbonates (2.46), residual (79.21) and residual (79.75) with TSE method; carbonates (2.36), residual (67.34) and residual (46.93) with SSE method. The Fe, Mn and Tl speciation scheme gives quantitative knowledge of toxicity, bioavailability, mobility, leachability and bioaccumulation, etc., for asphaltite. A comparison of the three methods shows that the TSE method is shorter and more economical, while SSE gives more detailed information about the chemical structure of the substances, and the BCRSE has reducible (as oxides) fractions for the metals. This is the first time that a comparison of the three extraction methods was carried out on asphaltites and reported. The certified reference material (CRM) NIST-1633b Coal Fly Ash was used to verify the accuracy of the method, and whether the results are in good agreement with the certified values.

\begin{tabular}{|c|c|c|}
\hline $\begin{array}{c}\text { Extraction } \\
\text { Methods }\end{array}$ & $\begin{array}{c}\text { Fraction } \\
\text { (S) }\end{array}$ & Nominal Fraction \\
\hline \multirow{4}{*}{ BCRSE } & Step 1 & Exchangeable + water and acid-Soluble (Carbonates) \\
\cline { 2 - 3 } & Step 2 & Reducible (Fe-Mn oxides) \\
\cline { 2 - 3 } & Step 3 & Oxidable (Bound to organic and sulfide) \\
\cline { 2 - 3 } & Step 4 & Residual content \\
\hline \multirow{4}{*}{ TSE } & Step 1 & Exchangeable \\
\cline { 2 - 3 } & Step 2 & Carbonates \\
\cline { 2 - 3 } & Step 3 & Oxidable (Bound to organic and sulfide) \\
\cline { 2 - 3 } & Step 4 & Residual content \\
\hline \multirow{4}{*}{ SSE } & Step 1 & Exchangeable \\
\cline { 2 - 3 } & Step 2 & Sorbed \\
\cline { 2 - 3 } & Step 3 & Organic bound \\
\cline { 2 - 3 } & Step 4 & Carbonates \\
\cline { 2 - 3 } & Step 5 & Sulfides \\
\cline { 2 - 3 } & Step 6 & Residual \\
\hline
\end{tabular}

\section{INTRODUCTION}

Asphaltites are unique natural raw materials and one group of solid natural bitumens. ${ }^{1}$ In the depths of the earth's crust, asphaltite is found in the liquid or semi-liquid state. Under the effects of hydrostatic pressure, gravitation, temperature, etc., asphaltites settle in the cracks and cavities of the earth, and contains $1.2 \%$ water, $4-7 \%$ sulfur and $35-40 \%$ ash. $^{2}$ Most asphaltite veins were formed in the Mesozoic-Cenozoic Era in SE Turkey. They contain large quantities of authigenic minerals similar to those precipitating within black shale, including clay minerals, quartz, albite, orthoclase and framboids of pyrite. ${ }^{3}$ It has a high thermal value, contains rare minerals and is used as solid fuel. Besides, it is suitable as a raw material for synthetic oil production. ${ }^{4}$ Turkey has asphaltite reserves totaling about 82 million tons. ${ }^{5}$

Some elements in asphaltites are potentially hazardous to the environment and some of them are highly carcinogenic and bioaccumulate in the body. Therefore, knowing the various forms of the elements and their oxidation states is very important. Speciation analysis is defined by IUPAC as the analytical activity involved in identifying and/or measuring the quantities of one or more individual chemical species in a sample. ${ }^{6}$ The definition of species is based on several different levels of the atomic and 
molecular structure where chemical forms of the same element are manifest. $^{7-12}$

Thallium is obtained as a by-product during the production of basic metals such as zinc. It acts together with cadmium during the production of zinc. Cadmium and thallium are separated by the distillation method. Thallium is also a very toxic element. It is used in agriculture, pharmacy, photography, electrical industry, production of various corrosion-resistant alloys and thermometer production. ${ }^{13,14}$ Twenty-five elements together with $\mathrm{Tl}$ were investigated and they can be found in coal in appreciable concentrations. The mode of occurrence of $\mathrm{Tl}$ is associated with pyrite. The mode of occurrence of $\mathrm{Mn}$ is in the form of carbonates, siderite and ankerite. ${ }^{15}$ It is an essential trace element known to be related particularly to the reproductive functions. Deficiency may lead to brain damage, teratogenicity, skeletal abnormalities, and abnormal metabolism of lipids and carbohydrates. Miners exposed to chronic Mn overload show symptoms of the extrapyramidal system, surprisingly similar to patients with Parkinson's disease. For this reason, Mn can become a highly toxic heavy metal, emitted from industrial sources, and seriously damage human health, affect the ecosystem and accumulate in the food chain. ${ }^{16,17}$

Iron is abundant in the earth's crust and occurs naturally in the aquatic environment; however, concentrations can be elevated due to human activities. Mining activities that expose pyrite and other sulfidic minerals to air and water lead to oxidation and release of iron and sulfuric acid in a process known as acid mine drainage (AMD). ${ }^{18}$

Although assessment of the total concentration of $\mathrm{Fe}$ and $\mathrm{Mn}$ in asphaltite is still useful in many areas, knowledge of their speciation is of primary importance because of their characteristic toxicity, mobility, bioavailability, and bioaccumulation depending on their different chemical fractions. The ICP-OES procedure is the most simple and reliable analytical method in the aqueous or solution phase for the elemental analysis of asphaltite due to its high selectivity and low interference problems. ${ }^{8}$ Electrothermal atomic absorption spectroscopy (ETAAS) with a graphite furnace, $\mathrm{X}$-ray fluorescence (XRF) and atomic absorption spectrometry (AAS) have also been used to determine $\mathrm{Fe}, \mathrm{Mn}$ and $\mathrm{Tl}$. Assessment of the chemical and morphological structure of asphaltites is important for their effective management.

The aim of the present research was to investigate the total concentration and distribution of $\mathrm{Fe}, \mathrm{Mn}$ and $\mathrm{Tl}$ (water-soluble, exchangeable, carbonate, reducible, oxidizable, sulfide and residual fractions) in asphaltite ash samples obtained at ŞırnakKaratepe, SE Turkey, and using the BCRSE, TSE and SSE extraction methods and analysis by ICP-OES. According to our literature survey, this comparison of the three sequential extraction methods and their speciation has not been reported previously.

\section{EXPERIMENTAL}

Reagents and Instrumentation. Reagents were of Suprapur, when available, or analytical grade (Merck, Germany) and used without further purification. Deionized distilled water was used throughout and obtained directly with a Milli-Q system (resistivity: 18.2 $\mathrm{M} \Omega \mathrm{cm}$ at $25^{\circ} \mathrm{C}$, Millipore Corporation, USA). Nitric acid $\left(\mathrm{HNO}_{3} 65 \%\right)$, hydrofluoric acid ( $\left.\mathrm{HF} 40 \%\right)$ and boric acid $\left(\mathrm{H}_{3} \mathrm{BO}_{3}\right.$, saturated solution) were of analytical grade reagents.

A Berghof MWS-3 model microwave digestion system (Berghof Co., Germany) was used for acid digestion of the asphaltite ash. The determination of $\mathrm{Mn}, \mathrm{Fe}$ and $\mathrm{Tl}$ was performed with a model Optima ${ }^{\mathrm{TM}} 2100$ DV inductively coupled plasma optical emission spectrometer (ICP-OES), (PerkinElmer, Inc., USA). Selection of the instrumental parameters and optical wavelength was based on obtaining good sensitivity, reasonable detection limits, and eliminating interferences. The limits of detection (LOD) for $\mathrm{Mn}, \mathrm{Fe}$ and $\mathrm{Tl}$ in ICP-OES were calculated as the concentration equal to 10 times the standard deviation of the background signal (the signal of the blank solution), which was multiplied by the dilution.

Sample preparation. The Karatepe flat is located in Karatepe, Şırnak, SE Anatolia, Turkey, near settlement areas. Its geographical coordinates are $44^{\circ} 52^{\prime} 15^{\prime \prime} \mathrm{N}, 20^{\circ} 38^{\prime} 25^{\prime \prime} \mathrm{E}$, and is about $2.3 \mathrm{~km}$ in length. Four inclined boreholes with a total depth of $307.3 \mathrm{~m}$ were drilled, $2950 \mathrm{~m}$ long and $1.50-12.00 \mathrm{~m}$ wide (average $5.50 \mathrm{~m}$ ). The asphaltite samples were obtained from a depth of $200 \mathrm{~m}$. Samples in the amount of about $20.0 \mathrm{~g}$ were collected and dried in a Memmert ULM 500 drying oven (Germany) at $105^{\circ} \mathrm{C}$, crushed in a Retsch BB1/A jaw crusher (Germany) and milled in a Retsch SRZ rotor beater mill. The particle sizes of the samples were sieved to a size of less than 100 $\mu \mathrm{m}$. The ash content, heating value, moisture and volatile matter contents of the samples were then determined according to the ASTM standard. ${ }^{12}$

For analysis, $20.0 \mathrm{~g}$ of asphaltite sample was weighed into a porcelain vessel and subjected to a muffle oven calcination at $800^{\circ} \mathrm{C}$ over a period of about $6 \mathrm{~h}$. The chemical analysis results of the asphaltite sample were obtained by a Carbolite brand (Serial no: $21-203261)$ ash furnace at $800^{\circ} \mathrm{C}$. According to the results of this analysis, the asphaltite sample had a high ash content of $48.51 \%$ and a low-calorie value. Afterwards, the elemental composition $(\mathrm{C}, \mathrm{N}, \mathrm{H})$ of the asphaltite samples was determined using a Carlo Erba elemental analyzer EA 1108. Table 1 lists the elemental and proximate analysis of the Karatepe, Şırnak, asphaltite.

Digestion procedure. Acid digestion of asphaltite incineration residues was performed with a Berghof MWS-3 microwave digestion system. In this process, microwave acid digestion was performed in two stages and five steps. Approximately $0.2 \mathrm{~g}$ of the 
Table 1. Elemental and Approximate Analysis of Karatepe, Şırnak, Turkey, Asphaltite

\begin{tabular}{ll}
\hline Elemental analysis & Content \\
\hline Carbon (\%) & 45.416 \\
Nitrogen (\%) & 1.085 \\
Hydrogen (\%) & 4.897 \\
Fe (\%) & $6.12 \pm 0.35$ \\
Mn (mg kg-1) & $126 \pm 5$ \\
Tl (mg kg-1) & $91.76 \pm 2.65$ \\
\hline Proximate analysis & \\
\hline Moisture (\%) & 0.602 \\
Ash (\%) & 48.51 \\
Volatiles (\%) & 16.03 \\
Total Sulphur (\%) & 4.062 \\
Lower Heat Value (Kcal g & \\
\hline
\end{tabular}

Table 2. Analytical Results of CRM NIST-1633b by the Proposed method

\begin{tabular}{llll}
\hline Element & Certified Value & Our value & Recovery $(\%)$ \\
\hline Fe (\%) & $7.78 \pm 0.23$ & $7.80 \pm 0.05$ & 100.38 \\
Mn $\left(\mathbf{m g ~ k g}^{-1}\right)$ & $131.8 \pm 1.7$ & $129.7 \pm 0,9$ & 98.41 \\
Tl $\left(\mathbf{m g ~ k g}^{-1}\right)^{*}$ & 5.9 & 6.0 & 101.7 \\
\hline
\end{tabular}

dried sample was weighed and transferred to a pressure-resistant polytetrafluoroethylene (PTFE) vessel. Then, a mixture of $10 \mathrm{~mL}$ $\mathrm{HNO}_{3}$ and $3 \mathrm{~mL} \mathrm{HF}$ acid was added to the material, the vessel closed and mounted in a sleeve for one hour. After removal, it was cooled to room temperature in a water bath. With the exception of the digestion program, the first stage of the method and the acid composition was the same as the one used for single-stage digestion. A $20 \mathrm{~mL}$ amount of $\mathrm{H}_{3} \mathrm{BO}_{3}$ reagent was added to the sample and the vessel returned to the microwave digestion system. The reaction mixture obtained after final digestion was subjected to an evaporation system to remove the acids. ${ }^{10}$ Subsequently, the residue was dissolved in water, filtered and the filtrate diluted to a constant volume of $50 \mathrm{~mL}$ with demineralized water. ${ }^{8}$ The NISTCRM 1633b constituent elements in Coal Fly Ash (National Institute of Standards and Technology, Gaithersburg, MD, USA) was used to check the accuracy of the analytical method. The results are listed in Table 2.

Analytical Procedure. The limits of detection (LOD) and limits of quantification (LOQ) for each metal were determined as follows: 10 independent analyses of a blank solution, spiked with the metal at a level of lower concentration of the analytical curve, were performed. The LOD and LOQ were calculated from the standard deviation $(\sigma)$ of these determinations (LOD $=3 \sigma$ and LOQ $=10 \sigma$ ). Table 3 lists the analytical performance results of ICP-OES.
Sequential extraction methods. The research by Tessier et al. ${ }^{19}$, Kersten and Forstner ${ }^{20}$, and Salomons and Forstner ${ }^{21}$ was based on the work of the Commission of the European Communities Reference Bureau (BCR). Hullebusch et al. ${ }^{22}$, Jegadeesan et al. ${ }^{23}$, and Lin et al. ${ }^{24}$ used the sequential extraction method widely to evaluate the mobility of trace metals.

The extraction procedure used in the present study is based on the determination of metals using potassium nitrate $\left(\mathrm{KNO}_{3}\right)$, sodium pyrophosphate $\left(\mathrm{Na}_{4} \mathrm{P}_{2} \mathrm{O}_{7}\right)$, potassium fluoride $(\mathrm{KF})$, nitric acid $\left(\mathrm{HNO}_{3}\right)$ and sodium ethylene-diamine-tetra-acetic acid (EDTA) reagents. ${ }^{25}$

\section{RESULTS AND DISCUSSION}

This study presents the speciation of $\mathrm{Fe}, \mathrm{Mn}$ and $\mathrm{Tl}$ in asphaltite from Şırnak-Karatepe, SE Anatolia, Turkey, by three different sequential extraction methods and a comparison of the results of these methods. The ICP-OES instrument was used for elemental analysis.

\section{BCRSE method}

The BCRSE method was used to study the Fe, Mn and $\mathrm{Tl}$ distribution in the Şırnak-Karatepe asphaltite samples. Four separate fractions (Exchangeable + water and acid-Soluble Fraction, Carbonates, Reducible (Fe-Mn oxides), Oxidizable (bound to organic and sulfide), residual contents were obtained. The operating conditions for the BCRSE method are listed in Table 4. In addition, the concentrations of the different $\mathrm{Fe}, \mathrm{Mn}$ and $\mathrm{Tl}$ fractions were determined using the BCRSE procedure for asphaltite, and the results are listed in Table 4.

\section{Results of BCRSE method}

Speciation of $\mathrm{Fe}, \mathrm{Mn}$ and $\mathrm{Tl}$ was carried out using a revised $\mathrm{BCR}$ method based on the sequential extractions from the asphaltite sample of $\mathrm{Fe}, \mathrm{Mn}$ and $\mathrm{Tl}$ forms: exchangeable, reducible, oxidizable, and residual fractions.

When Table 4 is considered, it was observed that the Fe content was between $0.19 \%$ and $2.28 \%$, and the Mn content about 45.80 $\mathrm{mg} \mathrm{kg}^{-1}$ in the reducible fraction and $75.85 \mathrm{mg} \mathrm{kg}^{-1} \mathrm{Mn}$ in the highest residual fraction. On the other hand, the amount of $\mathrm{Tl}$ in the exchangeable, reducible and oxidizable fractions ranged from about $3.17 \mathrm{mg} \mathrm{kg}^{-1}$ to $3.35 \mathrm{mg} \mathrm{kg}^{-1}$, while the highest value in the residual fraction was about $81.99 \mathrm{mg} \mathrm{kg}^{-1} \mathrm{~T} 1$. Thus, one can conclude that $81.99 \mathrm{mg} \mathrm{kg}^{-1} \mathrm{Tl}$ in the analyzed asphaltite sample is high and can be recovered by enriching it economically, since it

Table 3. Analytical Performance of the Proposed Method

\begin{tabular}{lccccc}
\hline Element & Linear Range $\left(\boldsymbol{\mu g} \mathbf{~ k g}^{-1}\right)$ & Regression & Correlation coefficient $\left(\mathbf{R}^{\mathbf{2}}\right)$ & $\mathbf{L O D}\left(\boldsymbol{\mu g} \mathbf{~ k g}^{-\mathbf{1}}\right)$ & $\mathbf{L O Q}\left(\boldsymbol{\mu g} \mathbf{~ k g}^{-1}\right)$ \\
\hline Fe & $0-100$ & $\mathrm{y}=127.61 \mathrm{x}+32.557$ & 0.9995 & 4.16 & 13.85 \\
$\mathbf{M n}$ & $0-100$ & $\mathrm{y}=1.0412 \mathrm{x}+0.291$ & 0.9993 & 6.97 & 23.21 \\
Tl & $0-100$ & $\mathrm{y}=2.6203 \mathrm{x}+0.752$ & 0.9989 & 8.92 & 29.70 \\
\hline
\end{tabular}


Table 4. Operating Conditions and Concentrations of Fe, Mn and Tl in Asphaltite Found by BCRSE, TSE and SSE Methods (n=3)

\begin{tabular}{|c|c|c|c|c|c|c|c|}
\hline $\begin{array}{l}\text { Extraction } \\
\text { Methods }\end{array}$ & $\begin{array}{c}\text { Fraction } \\
\text { (S) }\end{array}$ & $\begin{array}{l}\text { Nominal } \\
\text { Fraction } \\
\end{array}$ & Extractants & $\begin{array}{l}\text { Extraction } \\
\text { Conditions } \\
\end{array}$ & $\begin{array}{c}\mathrm{Fe} \\
(\%)\end{array}$ & $\begin{array}{c}\mathrm{Mn} \\
\left(\mathrm{mg} \mathrm{kg}^{-1}\right)\end{array}$ & $\begin{array}{c}\mathrm{Tl} \\
\left(\mathrm{mg} \mathrm{kg}^{-1}\right)\end{array}$ \\
\hline \multirow{4}{*}{ BCRSE } & Step 1 & $\begin{array}{l}\text { Exchangeable }+ \\
\text { water and } \\
\text { acid-Soluble } \\
\text { (Carbonates) }\end{array}$ & $\begin{array}{c}0.11 \mathrm{M} \mathrm{CH}_{3} \mathrm{COOH} \\
40 \mathrm{~mL}(\mathrm{pH}=7)\end{array}$ & Shaken $16 \mathrm{~h}, 20^{\circ} \mathrm{C}$ & $0.19 \pm 0.02$ & $1.26 \pm 0.11$ & $3.17 \pm 0.14$ \\
\hline & Step 2 & $\begin{array}{c}\text { Reducible } \\
\text { (Fe-Mn oxides) }\end{array}$ & $0.5 \mathrm{M} \mathrm{NH}_{2} \mathrm{OH}-\mathrm{HCl} 40 \mathrm{~mL}$ & Shaken $16 \mathrm{~h}, 20^{\circ} \mathrm{C}$ & $2.28 \pm 0.36$ & $45.80 \pm 1.15$ & $3.25 \pm 0.19$ \\
\hline & Step 3 & $\begin{array}{l}\text { Oxidable } \\
\text { (Bound to } \\
\text { organic and } \\
\text { sulfide) }\end{array}$ & $\begin{array}{c}20 \mathrm{~mL} \mathrm{H}_{2} \mathrm{O}_{2}(30 \%) \text { and } \\
\text { then } 50 \mathrm{~mL} \\
1 \mathrm{M} \mathrm{NH}_{4} \mathrm{CH}_{3} \mathrm{COO}\end{array}$ & $\begin{array}{c}\text { Shaken } 1,2,16 \mathrm{~h}, 20, \\
85,20^{\circ} \mathrm{C}\end{array}$ & $1.53 \pm 0.24$ & $2.09 \pm 0.15$ & $3.35 \pm 0.20$ \\
\hline & Step 4 & Residual content & $\begin{array}{c}\mathrm{HCl} / \mathrm{HNO}_{3}(3: 1) 10 \mathrm{ml} \\
\text { demineralized water and } \\
10 \mathrm{ml} \text { aqua regia }\end{array}$ & $\begin{array}{l}26 \text { min, } \\
\text { microwave oven }\end{array}$ & $2.12 \pm 0.32$ & $75.85 \pm 1.79$ & $81.99 \pm 1.74$ \\
\hline \multirow{4}{*}{ TSE } & Step 1 & Exchangeable & $1 \mathrm{M} \mathrm{NH}_{4} \mathrm{CH}_{3} \mathrm{COO} 10 \mathrm{ml}$ & Shaken $1 \mathrm{~h}, 20^{\circ} \mathrm{C}$ & $0.14 \pm 0.03$ & $1.43 \pm 0.16$ & $1.57 \pm 0.22$ \\
\hline & Step 2 & Carbonates & $1 \mathrm{M} \mathrm{CH}_{3} \mathrm{COOH} 10 \mathrm{ml}$ & Shaken $1 \mathrm{~h}, 20^{\circ} \mathrm{C}$ & $2.46 \pm 0.29$ & $43.74 \pm 0.59$ & $6.89 \pm 0.19$ \\
\hline & Step 3 & $\begin{array}{l}\text { Oxidable (Bound } \\
\text { to organic and } \\
\text { sulfide) }\end{array}$ & $\begin{array}{l}30 \% \text { solution of } \mathrm{H}_{2} \mathrm{O}_{2} \\
\quad(\mathrm{pH}=2) 5 \mathrm{ml}\end{array}$ & Shaken $3 \mathrm{~h}, 35^{\circ} \mathrm{C}$ & $1.57 \pm 0.18$ & $1.14 \pm 0.08$ & $3.51 \pm 0.27$ \\
\hline & Step 4 & Residual content & $\begin{array}{c}\mathrm{HCl} / \mathrm{HNO}_{3}(3: 1) 10 \mathrm{ml} \\
\text { demineralized water and } \\
10 \mathrm{ml} \text { aqua regia }\end{array}$ & $\begin{array}{l}26 \mathrm{~min}, \\
\text { microwave oven }\end{array}$ & $1.92 \pm 0.24$ & $79.21 \pm 0.92$ & $79.75 \pm 1.63$ \\
\hline \multirow{6}{*}{ SSE } & Step 1 & Exchangeable & $1 \mathrm{M} \mathrm{KNO}_{3} 30 \mathrm{~mL}$ & Shaken $16 \mathrm{~h}, 20^{\circ} \mathrm{C}$ & $0.09 \pm 0.01$ & $0.87 \pm 0.06$ & $1.79 \pm 0.13$ \\
\hline & Step 2 & Sorbed & $0.5 \mathrm{M} \mathrm{KF} 48 \mathrm{~mL}$ & Shaken $16 \mathrm{~h}, 20^{\circ} \mathrm{C}$ & $0.08 \pm 0.02$ & $0.73 \pm 0.02$ & $2.86 \pm 0.25$ \\
\hline & Step 3 & Organic bound & $0.1 \mathrm{M} \mathrm{Na}_{4} \mathrm{P}_{2} \mathrm{O}_{4} 48 \mathrm{~mL}$ & Shaken $16 \mathrm{~h}, 20^{\circ} \mathrm{C}$ & $1.07 \pm 0.06$ & $0.92 \pm 0.04$ & $3.98 \pm 0.18$ \\
\hline & Step 4 & Carbonates & $0.1 \mathrm{M}$ EDTA $48 \mathrm{~mL}$ & Shaken $16 \mathrm{~h}, 20^{\circ} \mathrm{C}$ & $2.36 \pm 0.25$ & $41.89 \pm 0.73$ & $7.07 \pm 0.34$ \\
\hline & Step 5 & Sulfides & $1 \mathrm{M} \mathrm{HNO}_{3} 30 \mathrm{~mL}$ & Shaken $16 \mathrm{~h}, 20^{\circ} \mathrm{C}$ & $1.94 \pm 0.10$ & $13.25 \pm 0.32$ & $29.16 \pm 0.61$ \\
\hline & Step 6 & Residual & $\begin{array}{c}\mathrm{HCl} / \mathrm{HNO}_{3}(3: 1) 10 \mathrm{~mL} \\
\text { demineralized water and } \\
10 \mathrm{~mL} \text { aqua regia }\end{array}$ & $\begin{array}{c}26 \mathrm{~min}, \\
\text { microwave oven }\end{array}$ & $0.58 \pm 0.04$ & $67.34 \pm 1.21$ & $46.93 \pm 1.27$ \\
\hline
\end{tabular}

is known that ores containing $10 \mathrm{~g} \mathrm{t}^{-1}$ or $10 \mathrm{mg} \mathrm{kg}^{-1}$ and higher in terms of thallium (T1) can be enriched. Hence, it can be said that the $\mathrm{Tl}$ values obtained in the asphaltite samples by the BCRSE extraction method do not pose environmental risks.

\section{TSE method}

The TSE method was used to study the Fe, Mn and Tl distribution in the Şırnak-Karatepe asphaltite samples. The concentrations of the different $\mathrm{Fe}, \mathrm{Mn}$ and $\mathrm{Tl}$ fractions were determined using the TSE procedure. The results and operating conditions for the TSE method are given in Table 4.

\section{Results of TSE method}

Fractionation of Fe, Mn and $\mathrm{Tl}$ was carried out using a modified Tessier method based on the sequential extractions from the asphaltite sample of the $\mathrm{Fe}, \mathrm{Mn}$, and $\mathrm{Tl}$ forms: exchangeable, carbonates, organic matter and sulfide, and residual fractions. When Table 4 is considered, it can be seen that the $\mathrm{Fe}$ concentration was between $0.14 \%$ and $2.46 \%$ and the $\mathrm{Mn}$ concentration was about $43.74 \mathrm{mg} \mathrm{kg}^{-1}$ in the carbonate fraction, and highest at $79.21 \mathrm{mg} \mathrm{kg}^{-1}$ in the residual fraction. Accordingly, it can be said that the amount of Mn obtained in the residual fraction of the TSE method in the asphaltite sample appears within harmful limits; however, this value is within acceptable limits considering the Mn values in the soil and plant. In addition, the enrichment methods can be applied to this fraction to be gained in different sectors. When the Mn values of the other methods and other fractions are compared, it is seen that it is normal.

On the other hand, the amount of T1 varied between about 1.57 $\mathrm{mg} \mathrm{kg}^{-1}$ and $6.89 \mathrm{mg} \mathrm{kg}^{-1}$ in the exchangeable, carbonates, organic matter-sulfide fractions, while the highest value in the residual fraction was about $79.75 \mathrm{mg} \mathrm{kg}^{-1} \mathrm{~T} 1$. It is known that ores containing $10 \mathrm{~g} \mathrm{t}^{-1}$ or $10 \mathrm{mg} \mathrm{kg}^{-1}$ and higher in terms of $\mathrm{T} 1$ have economic value; hence, it was concluded that $79.75 \mathrm{mg} \mathrm{kg}^{-1} \mathrm{Tl}$ in the analyzed asphaltite sample is high and can be obtained by enriching it economically.

\section{SSE method}

The SSE method was used to study the Fe, Mn, and Tl distribution in the Şırnak-Karatepe asphaltite samples. The SSE method was applied with six different fractions (exchangeable, sorbed, organic-bound, carbonates, sulfides, and residual fractions). The concentrations of the different $\mathrm{Fe}, \mathrm{Mn}$ and $\mathrm{Tl}$ fractions were determined using the SSE procedure. The operating conditions 
and the experimental results are listed in Table 4.

\section{Results of SSE Method}

The fractionations of $\mathrm{Fe}, \mathrm{Mn}$ and $\mathrm{Tl}$ were carried out using a revised Stover method based on the sequential extractions from the asphaltite sample of the $\mathrm{Fe}, \mathrm{Mn}$ and $\mathrm{Tl}$ forms: exchangeable, sorbed, organically bound, carbonates, sulfides and residual fractions.

When Table 4 is considered, it can be observed that the $\mathrm{Fe}$ concentration as $\%$ varies from about $0.08 \%$ to about $2.36 \%$. These ratios have no economic value for Fe enrichment. The $\mathrm{Mn}$ concentration was found to be about $13.25 \mathrm{mg} \mathrm{kg}^{-1}$ in the sulfides fraction, about $41.89 \mathrm{mg} \mathrm{kg}^{-1}$ in the carbonates fraction, and about $67.34 \mathrm{mg} \mathrm{kg}^{-1}$ in the highest residual fraction. The Mn values in the exchangeable, sorbed, and organic-bound fractions ranged from about $0.73-0.92 \mathrm{mg} \mathrm{kg}^{-1}$. Accordingly, the values in the asphaltite samples do not pose environmental risks.

On the other hand, the amount of $\mathrm{T} 1$ varied between about 1.79 $\mathrm{mg} \mathrm{kg}{ }^{-1}$ to $7.07 \mathrm{mg} \mathrm{kg}^{-1}$ in the exchangeable, sorbed, organicbound and carbonates fractions, while that in the sulfide fraction was about $29.16 \mathrm{mg} \mathrm{kg}^{-1}$, and the highest residual fraction was $46.93 \mathrm{mg} \mathrm{kg}^{-1}$. As the ore containing $10 \mathrm{~g} \mathrm{t}^{-1}$ or $10 \mathrm{mg} \mathrm{kg}^{-1}$ or higher in terms of $\mathrm{T} 1$ has economic value, it can be concluded that the $\mathrm{T} 1$ amount of $29.16 \mathrm{mg} \mathrm{kg}^{-1}$ and $46.93 \mathrm{mg} \mathrm{kg}^{-1}$ in the analyzed asphaltite sample is economically valuable, so it can be enriched.

\section{Comparison of $\mathrm{Fe}, \mathrm{Mn}$ and $\mathrm{Tl}$ element results according to BCRSE, TSE and SSE methods}

If the concentration of heavy metals in fly ash is high, they can present significant hazards to soil and water environments. The environmental behavior of heavy metals in toxic trace amounts is evaluated differently. The weak acid-soluble and water-soluble fractions belong to mobile fractions or biologically available fractions. The less unstable forms of these metals (oxidizable and reducible fractions) are considered to be low mobile fractions. In this order, the environmentally stable fraction deserves to be called a very low mobile fraction.

When the Fe, Mn and Tl results of the BCRSE, TSE and SSE methods applied in the asphaltite sample were compared, it was observed that the $\%$ amount of $\mathrm{Fe}$ was between $0.08 \%$ and $2.46 \%$. When considered in terms of ore enrichment, this trace amount of $\mathrm{Fe} \%$ in mining is generally seen as undesired impurities. When the ratios of $\mathrm{Mn}\left(\mathrm{mg} \mathrm{kg}^{-1}\right)$ were compared, it was seen that the highest values of all methods and fractions were found in the residual fractions. The highest ratio of $\mathrm{Mn}$ in the residual fraction of the TSE method was obtained as $79.21 \mathrm{mg} \mathrm{kg}^{-1}$. When the T1 $\left(\mathrm{mg} \mathrm{kg}^{-1}\right)$ values were compared, it was observed that the highest values of all methods and fractions were found in the residual fractions. The ratio of $\mathrm{Tl}$ in the asphaltite sample was $46.93 \mathrm{mg} \mathrm{kg}^{-1}$ with the SSE method and $81.99 \mathrm{mg} \mathrm{kg}^{-1}$ with the BCRSE method.

Iron (Fe): Fe was the major element in our ash. In ash, the most abundant form of Fe follows the order: reducible $>$ residual $>$ oxidizable $>$ exchangeable in BCRSE, carbonates $>$ residual $>$ oxidizable $>$ exchangeable in TSE, and carbonates $>$ sulfides $>$ organic-bound $>$ residual $>$ exchangeable $>$ sorbed in SSE.

We think for BCRSE, the majority of $\mathrm{Fe}$ is present as the refractory species, such as hematite, magnetite and ferric/ferrous species in our sample. ${ }^{24}$ However, Fe seemed to be as sulfate species, which may explain the fact that very little $\mathrm{Fe}(<0.2 \%)$ was present in the water/acid-soluble phase. ${ }^{23}$ In the case of the TSE methods, our results are different from those in the fly ash from Poland. ${ }^{19}$

Manganese (Mn): The most abundant form of Mn follows the order: residual $>$ reducible $>$ oxidizable $>$ exchangeable in $\mathrm{BCR}$, residual $>$ carbonates $>$ exchangeable $>$ oxidizable in Tessier, and residual $>$ carbonates $>$ sulfides $>$ organic-bound $>$ exchangeable $>$ sorbed in the SSE method.

In all three extraction methods, the residual form is high for the value for Mn. This result is different from that found by Nilufer Ozcan and Huseyin Altundag, ${ }^{26}$ but is the same as that of E. Varhan in BCR. ${ }^{27}$ In the SSE method, the residue and sulfides values are high for $\mathrm{Tl}$. This sequential extraction method gave detailed information on the chemical composition of ash.

Thallium (Tl): The most abundant form of $\mathrm{Tl}$ follows the order: residual $>$ oxidizable $>$ reducible $>$ exchangeable $>$ in BCRSE, residual $>$ carbonates $>$ oxidizable $>$ exchangeable in TSE, and residual $>$ sulfides $>$ carbonates $>$ organic-bound $>$ sorbed $>$ exchangeable in the SSE method. The results showed that the concentration of $\mathrm{Tl}$ in our samples was much higher in the residual fraction, and the exchangeable fraction was low for all extraction methods. For environmental pollution, this is a very important result.

\section{CONCLUSIONS}

The concentrations of $\mathrm{Fe}, \mathrm{Mn}$ and $\mathrm{Tl}$ in the asphaltite ash samples (Karatepe, Şırnak, SE Anatolia, Turkey) were determined by BCRSE (for exchangeable, reducible, oxidizable and residual fractions), TSE (for exchangeable, carbonates, oxidable and residual fractions), and SSE methods (for exchangeable, sorbed, organic bound, carbonates, sulfides and residual fractions). How metals bonded to the ore and the characteristics of the reactants are determined by the three methods.

The most abundant form of Fe follows the order: reducible $>$ residual $>$ oxidizable $>$ exchangeable in BCRSE, carbonates $>$ residual $>$ oxidizable $>$ exchangeable in TSE, and carbonates $>$ sulfides $>$ organic bound $>$ residual $>$ exchangeable $>$ sorbed in the SSE method.

The order for Mn follows: residual $>$ reducible $>$ oxidizable $>$ exchangeable in BCRSE, residual $>$ carbonates $>$ exchangeable $>$ oxidizable in TSE, and residual $>$ carbonates $>$ sulfides $>$ organic 
bound $>$ exchangeable $>$ sorbed in the SSE method.

Tl follows the order: residual $>$ oxidizable $>$ reducible $>$ exchangeable $>$ in BCRSE, residual $>$ carbonates $>$ oxidizable $>$ exchangeable in TSE, and residual $>$ sulfides $>$ carbonates $>$ organic-bound $>$ sorbed $>$ exchangeable in the SSE method.

It is understood that the harmful metals in asphaltite ash do not dissolve in water, and at $\mathrm{pH}$ 3-7 there is not much harm to the environment. However, this work and to recover these precious metals, especially $\mathrm{Tl}$ and $\mathrm{Mn}$, should be performed soon since it will contribute greatly to the national economy.

In conclusion, we would like to make the following remarks for comparison of the three sequential extraction methods: Compared to the other methods, the TSE method requires less time and is more economical, while SSE gives more information about the chemical structure of the substances. Although the BCRSE method is more time-consuming, it provides information about the reducible form of the metals. The SSE procedure gives more detailed fraction and decomposition knowledge and is, therefore, more suitable for asphaltite.

\section{AUTHOR INFORMATION}

\section{Corresponding Author}

*F. Aydin

Email address: faydin@dicle.edu.tr

\section{Notes}

The authors declare no competing financial interest.

\section{REFERENCES}

1. G. Gordadze, V. Kerimov, M. Giruts, A. Poshibaeva, and V. Koshelev, Fuel, 2018, 216, 835-842. https://doi.org/10.1016/j.fuel.2017.11.146

2. B. Çakır, M. Kılıç, and E. Kahraman, Journal of Çukurova University Faculty of Engineering and Architecture, 2013, 28, 99111.

3. J. Parnell, Proceedings of the 25 years SGA Anniversary Meeting Nanncy, 1991, 25, 573-576.

4. O. Bilgin and S. Kantarc1, Turkey $24^{\text {th }}$ International Mining Congress and Exhibition, 2015, Antalya-Turkey, 27-32.

5. I. Sengüler, TMMOB Turkey VI. Energy Symposium (Ankara) Global Energy Policies and Turkey Fact, 2007, 186-195.

6. D. M. Templeton, F. Ariese, R. Cornelis, L. G. Danielsson, H. Muntau, and H. P.V. Leeuwen, and R. Lobi'nski, Pure Appl. Chem. 2000, 72 , 1453-1470. https://doi.org/10.1351/pac200072081453

7. A. Sungur, M. Soylak, S. Yilmaz, and H. Ozcan, Environ. Earth Sci., 2014, 72, 3293-3305. https://doi.org/10.1007/s12665-014-3233-6

8. I. Aydin, B. Gunduz, F. Aydin, O. Akba, A. Saydut, and C. Hamamci, At. Spectrosc., 2014, 35, 241-246. https://doi.org/10.46770/AS.2014.06.002

9. I. Aydin, F. Aydin, and C. Hamamci, Microchem. J., 2013, 108, 64-67. https://doi.org/10.1016/j.microc.2012.12.001

10. I. Aydin, F. Aydin, and C. Hamamci, Fuel, 2012, 95, 481-485. https://doi.org/10.1016/j.fuel.2011.09.013

11. A. Sungur, M. Soylak, and H. Ozcan, Chem. Spec. Bioavailab., 2014, 26, 219-230. https://doi.org/10.3184/095422914X14147781158674

12. F. Aydin, B. Gunduz, I. Aydin, O. Akba, A. Saydut, and C. Hamamci, At. Spectrosc., 2013, 34, 140-145. https://doi.org/10.46770/AS.2013.04.005

13. O. L. Thomas, Thallium. Mineral Commodity Summaries, 1991, 1585.

14. DPT, Metal mines sub-commission advanced technology raw materials working group report, Eighth Five-Year Development Plan Mining Specialized Commission Report Ankara, 2001, 633, 29.

15. D. J. Swaine and F. Goodarzi (eds.), The Netherlands: Kluwer Academic Publishers, 1995.

https://doi.org/10.1007/978-94-015-8496-8

16. J. Kalembkiewicz, E. Sitarz-Palczak, and L. Zapala, Microchem. J. 2008, 90, 37-43. https://doi.org/10.1016/j.microc.2008.03.003

17. B. Isik, C. Hamamci and R. Isik, Asian J. Chem., 2006, 18, 1433-1436.

18. P. Cadmus, S. F. Brinkman and M. K. May, Arch. Environ. Contam. Toxicol., 2018, 74, 605-615. https://doi.org/10.1007/s00244-018-0505-2.

19. A. Tessier, P. G. C. Campbell and M. Bisson, Anal. Chem., 1979, 51, 844-851. https://doi.org/10.1021/ac50043a017

20. M. Kersten and U. Forstner, Water Sci. Technol., 1986, 18, 121-130.

21. W. Salomons and U. Forstner, Metals in the hydrogeocycle. Springer-Verlag, Berlin, Germany, 1984, 349, 149.

22. E. D. V. Hullebusch, S. Utomo, M. H. Zandvoort and P. N. L. Lens, Talanta, 2005, 65, 549-558. https://doi.org/10.1016/j.talanta.2004.07.024

23. G. Jegadeesan, R.A. Souhail, P. Patricio, Fuel, 2008, 87, 1887-1893. https://doi.org/ 10.1016/j.fuel.2007.12.007

24. R. Lin, M. Stuckman, B. H. Howard, T. L. Bank, E. A. Roth, M. K. Macala, C. Lopano, Y. Soong, and E. J. Granite, Fuel, 2018, 232, 124-133. https://doi.org/ 10.1016/j.fuel.2018.05.141

25. R. C. Stover, L. E. Sommers, and D. J. Silvera, J. Water Pollut. Control Fed., 1976, 48, 2165-2175.

26. N. Ozcan and H. Altundag, Bull. Chem. Soc. Ethiop., 2013, 27, 205212. http://dx.doi.org/10.4314/bcse.v27i2.5

27. E. V. Oral, At. Spectrosc., 2018, 39, 198-202. https://doi.org/10.46770/AS.2018.05.004 